\title{
Structural Integrity Assessment of the Welded Joints of the Constitution of 1812 Bridge (Cádiz, Spain)
}

\author{
M. A. Díaz García ${ }^{a}$, S. Cicero $^{\text {b}}$, O. R. Ramos Gutiérrez ${ }^{\mathrm{a}, \mathrm{c}}$ \\ aAPIAXXI Louis Berger IDC, Av. Albert Einstein 6, PCTCAN, 39011, Santander, Spain. \\ ${ }^{\mathrm{b}}$ LADICIM (Laboratory of Materials Science and Engineering), E.T.S. de Ingenieros de \\ Caminos, Canales y Puertos, University of Cantabria, Av/Los Castros 44, 39005, Santander, \\ Spain

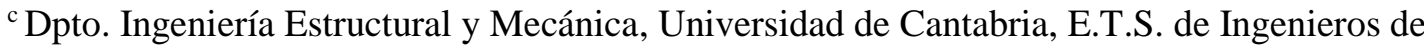 \\ Caminos, Canales y Puertos, University of Cantabria, Av/Los Castros 44, 39005, Santander, \\ Spain \\ * Corresponding author: mdiaz@louisberger.com
}

\begin{abstract}
As required by the current Spanish regulations, an inspection and maintenance plan has been completed for the Constitution of 1812 Bridge over the Bay of Cádiz (Spain), which defines the work to be performed on the different elements of the bridge during its service life. The part of the plan related to the inspection of the steel structure has a section dedicated to the inspection of the defects that may be present in the welded joints of the steel deck, providing critical defect sizes above which the safety of the structure would be compromised. With this purpose, in the most stressed points of the deck, the structural details that are most susceptible to fatigue and fracture phenomena have been identified. Moreover, fatigue tests of these details have been performed to complete a structural integrity assessment that also comprises the determination of the material fracture toughness and the definition of the corresponding critical crack sizes. The tests were carried out on specimens obtained with the same steel grades as those used in the bridge and with the same welding procedures as those practiced in the structure. The results show that the fatigue test results are above the S-N curves provided by the Eurocode 3, and also that numerous critical crack sizes would not be detected by the usual inspection techniques used in bridges (visual inspection), so that further research into how to manage this issue is recommended.
\end{abstract}


Keywords: Inspection, fatigue, fracture, structural integrity, steel deck.

\section{Introduction}

Following the latest revisions of Spanish standards such as EHE-08 [1], EAE [2] or IAP11 [3], more and more resources are being allocated during design and construction phases to the preparation of inspection and maintenance manuals that cover the complete life cycle of civil structures. These manuals define the tasks to be performed in the different elements of the structure being analysed, and the periodicity of these tasks until the end of the corresponding service life.

Requested by the "Ministry of Public Works and Transport" of Spain, these documents have been prepared for the Constitution of 1812 Bridge, located on the Bay of Cádiz (Cádiz, Spain) [4]. In this case, as part of the inspection of the metallic structure, a structural integrity analysis has been completed on the welded joints of the bridge deck, covering both fatigue and fracture assessments. The analysis determines, among others, the experimental S-N curves of the main structural details, as well as their corresponding critical crack size, something that, in principle, would allow the following points to be addressed:

- To analyse whether the fitness-for-service of the bridge is guaranteed

- To establish the corresponding safety margin against failure

- To establish inspection periods and strategies when no cracks are detected, and to modify such periods and strategies when cracks are found

- To establish the limits on the use of the bridge according to the defects found

Fracture assessments have been carried out following the BS7910 [5]. This standard (and others such as FITNET FFS [6] or API RP 579-1/ASME FFS-1 [7]) is widely applied in different industrial sectors, such as oil and gas (pipelines, tanks,...) and in the nuclear sector (pipes, vessels, ...), but its application to civil structures such as bridges is scarce (e.g., $[8,9])$. Moreover, as shown below, the critical crack sizes obtained through its application come into conflict with the fact that the inspection of bridges and their structural components is generally performed by means of 
visual inspection, whereas more sophisticated techniques (e.g., ultrasonic testing) are not applicable due to their high costs.

With all this, section 2 gathers a description of the bridge, section 3 identifies the most stressed parts of the bridge deck, section 4 describes the experimental program and the results obtained, section 5 gathers the structural integrity assessments and, finally, section 6 summarises the main conclusions.

\section{Basic description of the bridge}

The Constitution of 1812 Bridge on the Bay of Cádiz [4], see Figure 1, gives access to the city of Cádiz from the end of Puerto Real, giving rise to the third access to the city along with the isthmus to San Fernando and the Carranza Bridge.

It has a total length of $3,157 \mathrm{~m}$ with a $32.5 \mathrm{~m}$ width crosssection formed by three roadways separated by medians. Two of the roadways, with two lanes each, are intended for light and heavy traffic and the other roadway now serves as a bus lane, but in the future will host the tram that will link Cádiz with Puerto Real, see Figure 2.

The bridge can be divided into four stretches (starting from the Cádiz bank):

- Stretch 1: completing a length of $580 \mathrm{~m}$, it is composed of an initial span of $55 \mathrm{~m}$ and seven consecutive spans of $75 \mathrm{~m}$. The section of the deck is trapezoidal, with a height of $3 \mathrm{~m}$ (including a $0.3 \mathrm{~m}$ thick concrete slab) and maximum width of $33.2 \mathrm{~m}$. The height of the piers sustaining the bridge deck varies from $7.8 \mathrm{~m}$ up to $32.0 \mathrm{~m}$.

- Stretch 2: $150 \mathrm{~m}$ long, and known as the detachable bridge, it is composed of one span with a similar crosssection to that presented in the previous stretch.

- Stretch 3: corresponding to the cable-stayed bridge and its compensation spans. The main span is $540 \mathrm{~m}$ long, it is located between the main towers, and presents a $69 \mathrm{~m}$ clearance over the water. The two main towers are $187.1 \mathrm{~m}$ and $181.2 \mathrm{~m}$ high, respectively. The upper part of each tower (59.2 m high over the deck) gathers the anchorage elements of the 44 pairs of cables. The crosssection of the deck (see Figure 2) is analogous to that described for the first stretch. The analyses included in this article focuses on this cable- 
stayed viaduct. It was built by balanced cantilever, so in addition to the welded joints performed in the workshop on each of the sections, there are numerous welded joints executed on site. From a structural point of view, the bridge deck of the main span transmits loads to the main towers through the cables. The compensation spans, two on each side of the main span, transmit loads to the towers (through the cables) and compensate those loads transmitted from the main span.

- Stretch 4: $1200.7 \mathrm{~m}$ long, corresponds to the descent of the bridge towards the Puerto Real bank. It is actually composed of a prestressed concrete deck supported by 23 piers. The length of the spans varies gradually from $75 \mathrm{~m}$ to $32 \mathrm{~m}$.

\section{Identification of the most stressed parts of the bridge deck}

In order to determine the most stressed sections and points of the deck, several finite element models have been performed, on which the restrictions and actions foreseen in the original bridge project were imposed. Figure 3 shows an example of the results obtained for certain loading hypotheses.

In a first approach, the deck works in two different ways, depending on whether or not there are stay cables nearby. In those sections with stay cables, the transmission of forces and moments occurs perpendicular to the deck. This means that the transversal diaphragms act as simply supported beams that conduct the loads from the centre of the deck to the stay cables. Thus, both the concrete slab and the upper part of the diaphragms are in compression, whereas the lower steel plates of the deck are subjected to (transverse) tensile stresses (see Figure 4a); those sections of the deck without stay cables work in approximately the same way as one or two span beams supported by the piers and/or by the stay cable zones. These beams usually present longitudinal negative bending moments on the supports and longitudinal positive bending moments in the central zone of the spans (see Figure $4 b$ ).

Throughout this work, mention will be made of the different steel plates composing the metallic deck. In order to easily identify each of the plates, they have been given the identification shown in the scheme gathered in Figure 5. 
Eight critical deck sections were identified when considering the longitudinal stresses appearing on the upper points of the deck (plate 3), located at $886 \mathrm{~m}, 912 \mathrm{~m}, 1,084 \mathrm{~m}, 1,110 \mathrm{~m}, 1,385 \mathrm{~m}$, 1,655 m, 1,853 m and 1,960 m from the Cádiz blank. Analogously, eight critical sections were identified when considering the longitudinal stresses appearing at the lower points of the deck (plate 1 and lower part of plate 4): $814 \mathrm{~m}, 1,004 \mathrm{~m}, 1,063 \mathrm{~m}, 1,325 \mathrm{~m}, 1,600 \mathrm{~m}, 1,705 \mathrm{~m}, 1,763$ $\mathrm{m}$ and $1,935 \mathrm{~m}$. The resulting stresses are gathered in Table 1.

Concerning the transversal stresses on the diaphragms, these are quite similar in the different sections affected by the stay cables, with maximum values of $268 \mathrm{MPa}$ in plate 1 and $310 \mathrm{MPa}$ in plate 4.

Once the sections of the deck subjected to higher stresses were defined, the corresponding critical welded joints were identified. These joints are those that, because of their geometry and/or location, are subjected to higher stresses and, therefore, are more prone to fatigue and fracture processes. 4 types of sections were finally considered:

- The first joint is a butt weld executed following the manual procedure 136-FCAW according to UNE-EN ISO 4063 [10], see Figure 6.

- The second joint analysed is a T-welded joint (see the scheme in Figure 7).

- The third welded joint fulfils the requirements of the weld execution found on site. In some cases, the gap between the plates welded is greater than that which is strictly necessary to complete the welding process. In such cases, weld beads were first applied on the edges of the plates being joined and, secondly, once the weld root was executed, the whole weld was completed (regrowth), see Figure 8.

- Finally, the fourth joint is made between plates with different thicknesses and with a transition slope of 5/1, see Figure 9.

The joints have also been classified following the Eurocode 3 (EC3) [11], obtaining the corresponding FAT classes, as shown below. 


\section{Experimental program and results}

4.1. Hardness measurements and microstructural analyses

Taking into account the four types of welded joints being analysed, different coupons were fabricated in a workshop using the same material (steel grade $\mathrm{S} 355 \mathrm{~J} 2+\mathrm{N}$ ) as that used in the bridge and following the same welding procedures practiced in the structure, ensuring that the corresponding mechanical properties are fully representative of those developed on site. Tensile, fatigue and fracture specimens were machined from the coupons in order to characterise mechanically the joints, as well as material samples used to determine the material microstructure and hardness.

In order to analyse the microstructure of the different welded joints, the samples were prepared by polishing and etching with Nital to reveal the different regions in the welding area (base metal, Heat Affected Zone and weld material). In addition, microhardness (HV10) measurements of the different parts of the joints were completed.

The main conclusions obtained from the microstructural analysis and the hardness measurements are the following:

- The maximum hardness values in the base material, Heat Affected Zone (HAZ) and weld material were $189 \mathrm{HV} 10,304 \mathrm{HV} 10$ and $274 \mathrm{HV}$, respectively, with very similar values in the different types of welded joints. The hardness values obtained are adequate for the materials being analysed. Figure 10 shows an example of a hardness profile obtained in the butt weld sample.

- The observed microstructures correspond to the structural steel and the welded joint materials being analysed: ferritic-pearlitic microstructure in the base metal, acicular ferrite, perlite, bainite and martensite in the HAZ, and acicular ferrite corresponding to the weld material.

Given that the hardness values and the observed microstructures were very similar in the four different types of welded joints being analysed, the definition of both the tensile and fracture properties was completed from specimens extracted (only) from the simplest joint (butt weld). 


\subsection{Tensile tests}

Taking into account the four types of welded joints being analysed, different coupons were fabricated using the same materials (steel grade) used in the bridge and following the same welding procedures as those practiced in the structure, ensuring that the corresponding mechanical properties are fully representative of those developed on site. Tensile, fatigue and fracture specimens were machined from the coupons in order to characterise mechanically the joints.

The experimental program begins with the determination of the tensile properties of the base material, the weld material, and the Heat Affected Zone (HAZ). Tensile tests were carried out to compare them with the minimum requirements associated with $\mathrm{S} 355 \mathrm{~J} 2+\mathrm{N}$ [12] steel, which guarantees a minimum yield strength of $355 \mathrm{MPa}$, a minimum ultimate tensile strength of 470 $\mathrm{MPa}$ (for plates with a thickness $3<\mathrm{t}<100 \mathrm{~mm}$ ) and a minimum elongation at failure of $22 \%$. All the specimens were cylindrical, with a diameter of $10 \mathrm{~mm}$ and a gauge length of $60 \mathrm{~mm}$.

18 tensile tests were performed, 3 in each of the 6 conditions of interest: base material, weld and HAZ, all in both the longitudinal and the transverse directions to the weld joint (butt weld). Here, it is important to notice that in those specimens corresponding to weld and HAZ material in the transverse direction to the weld, the whole length of the specimens does not only contain the analysed material. As an example, weld material tensile specimens contain the weld material in the centre of the gauge length, followed by HAZ in on both sides and the central part, and finally, base material at both ends of the specimens. The tests were completed according to the standard EN ISO 6892-1 [13]. The main results are shown in Table 2.

After analysing the obtained data, it was possible to verify that the test specimens of the base material meet all the specifications corresponding to a $\mathrm{S} 355 \mathrm{~J} 2+\mathrm{N}$ steel; the tests on the weld material broadly exceed the minimum ultimate tensile strength specified for $\mathrm{S} 355 \mathrm{~J} 2+\mathrm{N}$ steels, while the values of ductility (strain at rupture) were lower than those specified for the base material; analogously, the specimens corresponding to the HAZ material provide values of the ultimate tensile strength well above those specified for S355J2+N steel, while the obtained ductility is below the specification. 


\subsection{Fatigue tests}

The fatigue behaviour of the weld joints has been determined. Again, the experimental analysis was performed through fatigue tests that were carried out on specimens extracted from test coupons obtained with the same material (steel grade) as that used in the bridge and according to the same welding procedures as those practiced in the structure. Each one of the four welded joints described above were characterised by testing 12 fatigue specimens at 6 different stress range levels, defining the corresponding S-N curve. Figure 11 shows an example of the geometry of the specimens. The tests have been carried out following the specifications of ASTM-E466-15 [14], with a stress ratio $(\mathrm{R})$ of 0.5 . This high value of the relation between the minimum and the maximum stresses was adopted for three reasons: a) it is a conservative value; b) the dead load in the bridge causes a significant average tensile stress in the welded joints being analysed, so 0.5 is a value that may be more representative of the real physics of the bridge, and; c) the existence of residual stresses in the welded joints provides high values of $\mathrm{R}$, in both the bridge and the specimens. This, in practice, means that the effect of the applied $\mathrm{R}$ in the fatigue performance of the welded joints is limited $[6,11,15]$, given that it is already intrinsically high. Concerning the frequency, all the tests were performed in a resonance machine, with frequencies around $80 \mathrm{~Hz}$. The run-outs were established at $10^{7}$ cycles.

The resulting S-N curves (and the corresponding FAT classes) will be compared to the FAT class used in the bridge project for the fatigue analysis, which was FAT 71 [11] for the four welded joints being analysed. Here, it should be noted that this implies a fatigue strength at $2 \cdot 10^{6}$ cycles of $71 \mathrm{MPa}$. Figure 12 shows the results (experimental points) obtained.

\subsection{Fracture tests}

The fracture resistance of the material (hereafter, $\mathrm{K}_{\mathrm{Jmat}}$ ) was determined by completing $\mathrm{K}_{\mathrm{J}}$ tests on $25 \mathrm{~mm}$ thick CT specimens. These were machined in such a way that the corresponding crack is located in the base material, the weld material and the HAZ, respectively, of a coupon containing a butt weld that was fabricated with the same materials as those used in the bridge and according to the same welding procedures as those practiced in the structure. The tests were completed according to ASTM E1820-17 [16]. 
18 tests were carried out, 3 in each of the 6 conditions of interest: base material, weld and HAZ, the three of them in both longitudinal and transverse directions to the joint.

The CT specimens were precracked with the load conditions specified in the standard until the crack length reached the following condition:

$$
0.45 \cdot W \leq a_{0} \leq 0.70 \cdot W
$$

where $\mathrm{W}$ is the width of the specimen and $\mathrm{a}_{0}$ is the crack length.

Taking into account that the fracture resistance of structural steels may suddenly decrease when the temperature drops within the material Ductile-to-Brittle Transition Zone, and in order to ensure a minimum fracture toughness regardless of the weather conditions to which the Constitution of 1812 Bridge is subjected, the fracture tests were carried out at $-20^{\circ} \mathrm{C}$ (the minimum temperature registered in Cádiz city is $-1^{\circ} \mathrm{C}$ ).

The fracture toughness of the material has been determined from the following expressions [16]:

$$
\begin{aligned}
& K_{\text {Jmat }}=\sqrt{\frac{E \cdot J_{m a t}}{1-v^{2}}} \\
& J_{m a t}=J_{e l}+J_{p l} \\
& J_{e l}=\frac{K_{I}^{2}\left(1-v^{2}\right)}{E} \\
& J_{p l}=\frac{\eta_{p l} \cdot A_{p l}}{B_{N} \cdot b_{0}}
\end{aligned}
$$

where $\mathrm{J}_{\text {mat }}$ is the $\mathrm{J}$-integral, $\mathrm{J}_{\mathrm{el}}$ is the elastic part of $\mathrm{J}_{\mathrm{mat}}, \mathrm{J}_{\mathrm{pl}}$ is the plastic part of $\mathrm{J}_{\mathrm{mat}}, \mathrm{K}_{\mathrm{I}}$ is the stress intensity factor, $v$ is the Poisson ratio, $\mathrm{E}$ is the Young's modulus, $\mathrm{A}_{\mathrm{pl}}$ is the (plastic) area under force vs. displacement curve (as defined in [16]) obtained in each individual test, $\mathrm{B}_{\mathrm{N}}$ is the net thickness of the specimen, and $\mathrm{b}_{0}$ is the initial remnant ligament $\left(\mathrm{W}-\mathrm{a}_{0}\right)$. Finally, for CT specimens, $\eta$ follows equation (6):

$$
\eta_{p l}=2+0.522 \frac{b_{0}}{W}
$$

The obtained results are shown in Table 3, which also shows the crack location and orientation (longitudinal vs. transveral to the weld), and how the different $\mathbf{J}_{\text {mat }}$ values (and the corresponding $\mathrm{K}_{\mathrm{Jmat}}$ values) are qualified $\left(\mathrm{J}_{\mathrm{c}}\right.$ or $\left.\mathrm{J}_{\mathrm{u}}\right)[16]$. 
It can be observed that most of the results are qualified as $\mathrm{J}_{\mathrm{u}}\left(\right.$ or $\left.\mathrm{K}_{\mathrm{Ju}}\right)$. This parameter is not considered a size-insensitive property and therefore it is a characteristic of the material and specimen geometry and size. On the contrary, $\mathrm{J}_{\mathrm{c}}\left(\right.$ or $\left.\mathrm{K}_{\mathrm{Jc}}\right)$ values are considered to be insensitive to the in-plane dimensions of the specimen.

The lowest fracture resistance values were obtained in the base material, for cracks oriented longitudinally to the weld. Following the MOTE (Minimum Of Three Equivalent) criterion suggested in BS7910 [5], the minimum value of the three experimental results will be considered here $\left(\mathrm{K}_{\mathrm{Jmat}}=125.9 \mathrm{MPam}^{1 / 2}\right)$. Given the uncertainty about the location and orientation of hypothetical cracks, this value will be conservatively considered in all the fracture assessments shown below.

\section{Structural integrity assessments}

\subsection{Fatigue assessments}

The main purpose of this section is to compare the experimental fatigue results with the design curves used for the bridge (FAT 71 in the four cases of welded joints being analysed). Figure 12 reveals how the different experimental points are well above the FAT71 design curve. Therefore, the assumption of the FAT71 curve as the fatigue design curve of the different welded joints being analysed is conservative.

Moreover, the fatigue tests performed allow the specific FAT class to be determined for a particular type of welded joint. With this purpose, the statistical procedure proposed by Eurocode 3 [11] will be followed. The S-N curves follow equation (7):

$\log N=\log A_{\text {design,tests }}-3 \cdot \log \Delta \sigma$

where

$\log A_{\text {design,tests }}=\log A_{\text {mean,tests }}-\mathrm{k} \cdot S t d v$

$S t d v$ is the standard deviation associated to each detail category (e.g., welded joint). The resulting $\log \mathrm{A}_{\text {design,tests }}$ is a characteristic value at a $\alpha=95 \%$ survival probability calculated from the mean value ( $\log \mathrm{A}_{\text {mean,tests }}$ ) on the basis of twosided tolerance limits of the $75 \%$ confidence level $(\beta)$ of 
the mean $\left(\log A_{\text {mean,tests }}\right)$ [17]. This follows equation (9), as proposed by the International Institute of Welding [17]:

$\mathrm{k}=\frac{t(p, n-1)}{\sqrt{n}}+\varphi_{(\alpha)}^{-1}=\frac{t(0.875, n-1)}{\sqrt{n}}+1.645$

where $t$ is the value of the onesided $\mathrm{t}$-distribution for a probability of $p=(1+\beta) / 2=0.875$ at $\mathrm{n}-1$ degrees of freedom, $\mathrm{n}$ is the number of tests performed, and $\varphi$ is a distribution function of the Gaussian normal distribution probability of exceedance of $\alpha=95 \%$.

Once the value of $\log A_{\text {design,tests }}$ has been calculated for each type of welded joint, the corresponding FAT class is obtained by using equation (10):

$F A T_{\text {design,tests }}=10^{\frac{\left(\log A_{\text {design,tests }}\right)-\log \left(2 \cdot 10^{6}\right)}{3}}$

The results obtained show that the FAT class for butt weld, T weld, re-growth weld and transition weld are $68.77,85.18,79.69$ and 75.57 , respectively. The corresponding fatigue experimental curves are also shown in Figure 12. There are three cases where the derived fatigue curves are well above the design curves, whereas in one case (butt weld) the experimental curve is below the design curve. This is caused by the high scatter obtained in the experimental results and the limited number of tests performed, something that implies a high Stdv value in equation (8) and lowers the corresponding curve. However, it can be clearly observed how the individual experimental results imply higher fatigue resistance than that defined by the Eurocode FAT71 curve. Figure 12 shows the graph with the fatigue results of the T-joint specimens.

The obtained curves (and the Eurocode FAT71 curve) are valid as long as the thickness of the plates is below $25 \mathrm{~mm}$ (as it is the case for the tested specimens, which are exactly on the limit of applicability). For higher thicknesses, the fatigue strength is expected to be lowered due to a combination of statistical effects (the thicker the plate, the higher the probability of finding fatigue initiation sites) and more complex stress states. Consequently, the obtained fatigue strength defined for thicknesses below $25 \mathrm{~mm}$ must be reduced by using a thickness correction factor $\left(\mathrm{k}_{\mathrm{s}}\right)$, which, in the case of the Eurocode 3 [11] is:

$k_{S}=\left(\frac{25}{T}\right)^{0.2}$ 
$\mathrm{T}$ being the corresponding plate thickness (in $\mathrm{mm}$ ).

Summarising, the fatigue experimental results demonstrate that the design curves used at the design stage of the bridge are conservative and, therefore, the fatigue life of the different welded joints being analysed will generally be higher than that expected originally.

\subsection{Fracture assessments}

The characterisation of the fracture-plastic collapse behaviour of the welded joints present in the Constitution of 1812 bride has been carried out by determining the (critical) crack size that jeopardises the safety of the structure. For this purpose, the minimum mechanical properties explained above have been considered $\left(\sigma_{\mathrm{y}}=355 \mathrm{MPa}, \sigma_{\mathrm{u}}=507.2 \mathrm{MPa}\right.$, and $\left.\mathrm{K}_{\mathrm{Jmat}}=125.9 \mathrm{MPam}^{1 / 2}\right)$, together with the tensile mechanical stresses gathered in section 3. For plate thicknesses $(\mathrm{T}$, in $\mathrm{mm}$ ) above $25 \mathrm{~mm}, \mathrm{~K}_{\mathrm{Jmat}}$ was obtained from equation (12) [18]:

$K_{\text {mat }}^{T}=K_{\text {mat }}^{25}\left(\frac{25}{T}\right)^{0.25}$

The assessments have been made using the Failure Diagram defined by British Standard 7910 [5] Option 1, where only the tensile properties of the material (yield strength and tensile strength) are required.

The structural component being analysed is defined by a point of coordinates $\left(\mathrm{K}_{\mathrm{r}}, \mathrm{L}_{\mathrm{r}}\right)$ :

$K_{r}=\frac{K_{I}}{K_{m a t}}$

$L_{r}=\frac{\sigma_{r e f}}{\sigma_{y}}$

where $K_{r}$ represents the situation against fracture, $L_{r}$ represents the situation against plastic collapse, $\mathrm{K}_{\mathrm{I}}$ is the stress intensity factor, $\mathrm{K}_{\mathrm{mat}}$ is the fracture resistance of the material (here, $\mathrm{K}_{\mathrm{Imat}}$, as explained above), $\sigma_{\text {ref }}$ is the reference stress, and $\sigma_{\mathrm{y}}$ is the material yield stress.

Failure takes place when the assessment point lies on the Failure Assessment Line (FAL), as shown in Figure 13.

The FAL established by BS7910 Option 1 [5] follows equations (15) to (22):

$$
\begin{array}{ll}
K_{r}=\left(1+\frac{1}{2} L_{r}^{2}\right)^{-1 / 2} & \mathrm{~L}_{\mathrm{r}}<1 \\
K_{r}=\left(\lambda+\frac{1}{2 \lambda}\right)^{-1 / 2} & \mathrm{~L}_{\mathrm{r}}=1
\end{array}
$$




$$
\begin{array}{ll}
K_{r}=K(1) L_{r}{ }^{(N-1) / 2 N} & 1<\mathrm{L}_{\mathrm{r}}<\mathrm{L}_{\mathrm{rmax}} \\
K_{r}=0 & \mathrm{~L}_{\mathrm{r}} \geq \mathrm{L}_{\mathrm{rmax}} \\
N=0,3\left(1-\frac{\sigma_{y}}{\sigma_{u}}\right) & \\
\lambda=1+\frac{E \Delta \varepsilon}{\sigma_{y}} & \\
\Delta \varepsilon=0,0375\left(1-0,001 \sigma_{y}\right) & \\
L_{r \max }=\frac{1}{2} \frac{\sigma_{y}+\sigma_{u}}{\sigma_{y}} &
\end{array}
$$

In the assessment, three different types of cracks have been assumed: through thickness crack, semielliptical crack with aspect ratio of 0.1 , and semielliptical crack with aspect ratio of 0.5 . The initiation of fracture has been analysed (no ductile tearing) [5,6] and the mismatch effect $[5,6]$ has not been taken into account, hypotheses that provide (if minimum mechanical properties are considered) an additional safety margin against the final failure.

The reference stress $\left(\sigma_{\text {ref }}\right)$ values were obtained from the compendium of solutions gathered in BS 7910 [5]. For a through thickness crack in an infinite plate:

$\sigma_{\text {ref }}=\frac{P_{b}+\left(P_{b}^{2}+9 P_{m}^{2}\right)^{1 / 2}}{3\left[1-\left(\frac{2 a}{W}\right)\right]}$

where $\mathrm{P}_{\mathrm{b}}$ is the primary bending stress, $\mathrm{P}_{\mathrm{m}}$ is the primary membrane stress, $\mathrm{a}$ is the half crack length, and $\mathrm{W}$ is the plate width (here, W > a). For a semielliptical crack in an infinite plate:

$\sigma_{r e f}=\frac{P_{b}+\left(P_{b}^{2}+9 P_{m}^{2}\left(1-\alpha^{\prime \prime}\right)^{2}\right)^{1 / 2}}{3\left(1-\alpha^{\prime \prime}\right)^{2}}$

$\alpha^{\prime \prime}=\frac{2 a / B}{1+(B / c)}$

where a is the crack height, $\mathrm{c}$ is the half crack length, and B is the plate thickness. The secondary stresses (residual stresses caused by the welding process) do not affect the reference stress.

The definition of the stress intensity factor $\left(\mathrm{K}_{\mathrm{I}}\right)$ requires taking into account both the mechanical stresses acting on the structure (primary) and residual (secondary) stresses caused by the welding process. The residual stresses proposed by BS 7910 [5] vary depending on the type of welded 
joint being analysed. As an example, residual stresses in butt welds follow equations (26) and (27):

$Q_{m}=0.311 * \sigma_{y}$

$Q_{b}=\left[0.289-0.578\left(\frac{z}{B}\right)\right] \sigma_{y}$

where $\mathrm{Q}_{\mathrm{m}}$ is the membrane component and $\mathrm{Q}_{\mathrm{b}}$ is the bending component, $\mathrm{z}$ being the depth at which residual stresses are being defined.

In the case of $T$ welds, residual stresses follow equations (28) and (29):

$Q_{m}=0.5 * \sigma_{y}$

$Q_{b}=\left[0.5-\left(\frac{z}{B}\right)\right] \sigma_{y}$

With all this, $\mathrm{K}_{\mathrm{I}}$ is finally defined by:

$K_{I}=\left[(Y \sigma)_{p}+(Y \sigma)_{s}\right] \sqrt{\pi a}+K_{s b}$

where $(\mathrm{Y} \sigma)_{\mathrm{p}}$ is the primary stress intensity correction function, $(\mathrm{Y} \sigma)_{\mathrm{s}}$ is the secondary stress intensity factor correction function, $\mathrm{a}$ is the crack size, and $\mathrm{K}_{\mathrm{sb}}$ is the self-balancing component of the residual stress profile

$(Y \sigma)_{p}=M f_{w}\left\{M_{k m} M_{m} P_{m}+M_{k b} M_{b} P_{b}\right\}$

$(Y \sigma)_{s}=\left\{M_{m} Q_{m}+M_{b} Q_{b}\right\}$

$\mathrm{M}$ and $\mathrm{f}_{\mathrm{w}}$ are correction factors related with the crack size (here equal to 1.0 in all cases), $\mathrm{M}_{\mathrm{Km}}$ are $\mathrm{M}_{\mathrm{Kb}}$ stress intensity magnification factors related to local stress concentrations (also equal to 1.0), $M_{m}$ and $M_{b}$ are stress intensity magnification factors related with the crack geometry. For through thickness cracks in an infinite plate, both $\mathrm{M}_{\mathrm{m}}$ and $\mathrm{M}_{\mathrm{b}}$ are equal to 1.0 [5]. In the case of a semielliptical crack in an infinite plate [5] (see Figure 14):

$$
\begin{aligned}
& M_{m}=\left[M_{1}+M_{2}\left(\frac{a}{B}\right)^{2}+M_{3}\left(\frac{a}{B}\right)^{4}\right] \frac{g f_{\theta}}{\Phi} \\
& M_{1}=1.13-0.09\left(\frac{a}{c}\right) \\
& M_{2}=\left[\frac{0.89}{0.2+(a / c)}\right]-0.54 \\
& M_{3}=0.5-\frac{1}{0.65+a / c}+14\left(1-\frac{a}{c}\right)^{24}
\end{aligned}
$$




$$
\begin{aligned}
& g=1+\left[0.1+0.35\left(\frac{a}{B}\right)^{2}\right](1-\sin \theta)^{2} \\
& f_{\theta}=\left[\left(\frac{a}{c}\right)^{2} \cos ^{2} \theta+\sin ^{2} \theta\right]^{0.25} \\
& \Phi=\left[1+1.464\left(\frac{a}{c}\right)^{1.65}\right]^{0.5} \\
& M_{b}=H M_{m} \\
& H=H_{1}+\left(H_{2}-H_{1}\right) \sin ^{q} \theta \\
& q=0.2+\left(\frac{a}{c}\right)+0.6\left(\frac{a}{B}\right) \\
& H_{1}=1-0.34\left(\frac{a}{B}\right)-0.11\left(\frac{a}{c}\right)\left(\frac{a}{B}\right) \\
& H_{2}=1+G_{1}\left(\frac{a}{B}\right)+G_{2}\left(\frac{a}{B}\right)^{2} \\
& G_{1}=-1.22-0.12\left(\frac{a}{c}\right) \\
& G_{2}=0.55-1.05\left(\frac{a}{c}\right)^{0.75}+0.47\left(\frac{a}{c}\right)^{1.5}
\end{aligned}
$$

Finally, concerning $\mathrm{K}_{\mathrm{sb}}$, it follows equations (47) and (48), respectively, for butt welds and $\mathrm{T}$ joints:

$$
\begin{aligned}
& K_{s b}=0.347 * \sigma_{y} \sqrt{B} \\
& K_{s b}=0
\end{aligned}
$$

Tables 4 to 7 show the critical crack values $\left(a_{c}\right)$ obtained at specific positions on the deck and for the 3 hypotheses of crack geometries being considered. For a correct interpretation, it is necessary to take into account that in the case of through thickness cracks, $a_{c}$ is the half-length of the defect observed in surface whereas in the semielliptical cracks the size of the crack width observed in surface is 2 and 10 times greater than $\mathrm{a}_{\mathrm{c}}$ aspect ratios of 0.5 and 0.1 , respectively.

The obtained critical sizes, derived from conservative assumptions, allow decisions to be taken after the corresponding inspections (e.g., need for repairs when the size of the detected cracks is close to the critical size, definition of inspection periods, etc). However, it can be observed how some of the critical crack sizes imply surface dimensions of 4-5 mm: an example could be a semielliptical surface crack in section $1935 \mathrm{~m}$ with $\mathrm{a} / 2 \mathrm{c}=0.5$ and located in a $\mathrm{T}$ weld (Table 6). 
The surface dimension of such a crack would be $4.4 \mathrm{~mm}(2.2 \times 2)$. This, in practice, constitutes an important issue, given that inspections in this kind of structures are generally performed by visual inspection, which is a technique whose sensitivity would not, in practice, allow such crack sizes to be detected. If, for example, it is assumed that only those cracks with surface dimensions above $15 \mathrm{~mm}$ would be detected, all those values in bold characters in tables 4 to 7 would represent situations in which the critical sizes would not be detected in a visual inspection. In such cases, alternative approaches should be considered: refinement of the analysis to derive larger crack sizes, analysis of structural redundancies, assessment of the possibility of using other inspection techniques like structural vibration monitoring using modal analysis, etc. In any case, whichever are the future approaches followed to ensure the structural integrity of the bridge, the definition of the existing cracks is an essential input of the analysis, so the maintenance plan of the bridge should include adequate inspection or detection procedures.

\section{Conclusions}

This paper presents a global methodology for ensuring the structural integrity of the welded joints of big bridges, based on the study of the Constitution of 1812 Bridge (Cádiz, Spain). It includes, from the structural analysis performed in the cable-stayed bridge design, the location of the most stressed points, the identification of the different welded joints to be analysed and an experimental program that includes microstructural analysis, hardness measurements, tensile testing, fatigue testing and fracture testing.

Assuming that the fatigue test welded coupons are representative of the welded joints existing on the bridge, the results demonstrate that the original fatigue design, based on the assumption of welded joints following the FAT71 EC3 curve, is safe, given that the experimental fatigue results are all well above the FAT71 design curve.

Concerning the fracture-plastic collapse analysis, it was performed following the BS7910, and has derived the different critical crack sizes for the subsequent combinations of bridge location, welded joint, crack geometry and crack orientation. In practice, a number of the resulting crack sizes could not be detected in the corresponding ordinary visual inspection, so alternative 
approaches are recommended in the near future in order to ensure that cracks are detected before they reach their corresponding critical size.

\section{Acknowledgments}

The authors of this work would like to express their gratitude to the University of Cantabria for the financial support of the project "Aplicación de Técnicas de Integridad Estructural y Fiabilidad de Materiales en la Determinacion del Ciclo de Vida de Puentes Metalicos y Mixtos- Application of Structural Integrity and Materials Reliability Techniques to the Life-Cycle Assessment of Metallic and Steel-Concrete Composite Bridges" (03.DI09.649), programme of industrial doctorates, on the results of which this paper is based.

\section{References}

[1] Instrucción de hormigón estructural EHE-08, Ministerio de Fomento, Spain, 2008.

[2] Instrucción de acero estructural EAE. Ministerio de Fomento, Spain, 2011.

[3] Instrucción sobre las acciones a considerar en el proyecto de puentes de carretera IAP-11. Ministerio de Fomento, Spain, 2011.

[4] F. Pedrazo Majárrez, Introducción al Puente de la Constitución de 1812 sobre la bahía de Cádiz, Hormig. Acero 67 (2016) 278-279.

[5] BS 7910 2013, Guide to methods for assessing the acceptability of flaws in metallic structures, British Standards Institution, London, 2013.

[6] FITNET FFS Procedure, Final Draft MK7, Prepared by European Fitness- for-Service Network- FITNET, 2006.

[7] API RP 579-1/ASME FFS-1, Fitness-For-Service, $3^{\text {rd }}$ Edition, American Petroleum Institute, Washington DC, 2016.

[8] S.K. Clubley, S.N. Winter, On the fatigue and fracture of site splice welds at the River Mardle viaduct, Eng. Fail. Anal. 10 (2003) 593-604.

[9] J. Terán-Guillén, S. Cicero, T. García, J.A. Álvarez, M. Martínez-Madrid, J.T. Pérez-Quiroz, Structural integrity assessment of the cast steel upper anchorage elements used in a cable stayed 
bridge, Eng. Struct. 81 (2014) 309-317.

[10] UNE-EN ISO 4063, Soldeo y técnicas conexas. Nomenclatura de procesos y números de referencia, AENOR, Spain, 2011.

[11] EN 1993-1-9. Eurocode 3: Design of steel structures - Part 1-9: Fatigue, European Committee for Standardization (CEN), Brussels, 2005.

[12] UNE-EN 10027-1:2017, Designation systems for steels - Part 1: Steel names, European Committee for Standardization (CEN), Brussels, 2017.

[13] EN ISO 6892-1:2016, Metallic materials -Tensile testing - Part 1: Method of test at room temperature, European Committee for Standardization (CEN), Brussels, 2016.

[14] ASTM E466-15, Standard Practice for Conducting Force Controlled Constant Amplitude Axial Fatigue Tests of Metallic Materials, ASTM International, West Conshohocken, PA, 2015. [15] BS 7608: 2013, Code of practice for fatigue design and assessment of steel structure, British Standard Institution, London, 2013.

[16] ASTM E1820-17, Standard Test Method for Measurement of Fracture Toughness, ASTM International, West Conshohocken, PA, 2017.

[17] XIII-1965-03/XV-1127-03, Recommendations for fatigue design of welded joints and components, International Institute of Welding (IIW), Paris, 2009.

[18] ASTM E1921-17a, Standard Test Method for Determination of Reference Temperature, To, for Ferritic Steels in the Transition Range, ASTM International, West Conshohocken, PA, 2017. 